\title{
Phosphorus Rates on Growth Parameters of Maize (Zea mays L.) in Reddish Brown Earth under Greenhouse Condition
}

\author{
Duminda D.M.S. ${ }^{* 1}$, Indraratne S.P. ${ }^{2}$ and Kumaragamage D. ${ }^{3}$ \\ ${ }^{1}$ Department. of Soil and Water Resources Management, Faculty of Agriculture, Rajarata University \\ of Sri Lanka, Anuradhapura, Sri Lanka \\ ${ }^{2}$ Department of Soil Science, Faculty of Agriculture, University of Peradeniya, Peradeniya, Sri Lanka \\ ${ }^{3}$ Department of Environmental Studies and Sciences, University of Winnipeg, \\ Manitoba, Canada \\ *dmsduminda@yahoo.com
}

\begin{abstract}
Phosphorus is an essential element for plants. However, many soils lack sufficient in form that is readily available to crops to ensure optimum growth especially in dry zone soils in Sri Lanka. Hence, this study was undertaken with the objective of evaluating the impact of different rates of Triple Super Phosphate (TSP) as a source of Phosphorus for maize (Var. Sampath) growth under greenhouse condition. Top soils at a depth of 0-25 cm were collected from research farm, Puliyankulama and from a farmland in Kahatagasdigiliya, Anuradhapura district. Greenhouse experiment conducted for both soils. Twenty pots were arranged in a completely randomized design with four treatments $\left(0,20,30\right.$ and $40 \mathrm{~kg}$ of Phosphorus ha $\left.{ }^{-1}\right)$ and five replicates for a single experiment. Soil samples were taken at 4, 8, 10, 12 and 16 weeks after planting (WAP). The soil samples were analysed for soil $\mathrm{pH}$, electrical conductivity (EC) and available Phosphorus (Olsen's method). The leaf Phosphorus content at $50 \%$ tasseling stage was measured using dry ash method. The growth parameters were plant heights at 4, 8, 10 and 12 WAP, number of days to $50 \%$ tasseling and number of days to $80 \%$ silking. Results indicate soil $\mathrm{pH}, \mathrm{EC}$, and leaf Phosphorus $\%$ are not significantly different $(\mathrm{p}<0.05)$ at different levels of Phosphorus in both locations. However, soil available Phosphorus is significantly different $(\mathrm{p}<0.05)$ to the control. Conversely it does not show significant different $(\mathrm{p}<0.05)$ among fertilized treatments at both sites. Moreover, plant height at $50 \%$ tasseling stage, number of days to $50 \%$ tasseling and number of days to $80 \%$ silking are not significantly different $(\mathrm{p}<0.05)$ among any treatments at both soil types. Hence, the results further revealed that the different levels of $\mathrm{P}$ treatments have no significant effect on soil $\mathrm{pH}$, EC, available $\mathrm{P}$, leaf $\mathrm{P}$ and growth parameters of maize variety Sampath under greenhouse conditions.
\end{abstract}

Keywords: Growth, Maize (Zea mays L.), Phosphorus, Reddish brown earth 